不同升温速率 $\beta$ 所对应的脱水过程的蜂温 $T_{m}$, 代人公式 $d\left[\ln \left(\beta / T_{m}^{2}\right)\right] / d\left(1 / T_{m}\right)=$ $-E / R$, 最小二乘法处理得到的脱水表观活 化能 $E$ 见机理箭头下方数据(单位 $\mathrm{kJ} / \mathrm{mol}$ ).
[2] Sadtler 标准.

[3] Jean-Claude, B. G., Helv. Chim. Acte., 2(1978), $762-771$.

高胜利 姜相武丁云龙

(西北大学化学系,西安)

\title{
参考文 塥
}

[1 ] 扬祖培等, 中国稀土学报, 4(1988), 83-85.

\section{估算金属熔化热和熔化摘的经验公式}

金属的熔化热和熔化摘是金属的重要性 质, 在理论研究和实际应用方面都有一定的 重要性.

根据 Richards 的研究, 固体变成液体 时的熔化热 $\tilde{L}_{m}$ 与熔化摘 $\Delta \tilde{S}_{m}$ 之间有与 Trouton 规则相似的关系式

$$
\Delta \tilde{S}_{m}=\tilde{L}_{m} / T_{m}=2.1 n,
$$

式中 $n$ 为结构原子数. 该式用来计算金属的 熔化摘,其结果较为满意.

我们在详细分析了金属的熔化热 $\tilde{L}_{m}$ 与 熔化摘 $\Delta \tilde{S}_{m}$ 实验数据的基础上, 总结出如 下经验规则

$$
\begin{aligned}
\Delta \tilde{S}_{m} & =\tilde{L}_{m} / T_{m} \\
& =9.3026+248.26 T_{m}^{-1},
\end{aligned}
$$

式中 $T_{m}$ 为金属的熔点, 单位为 $\mathrm{K}, \hat{L}_{m}$ 和

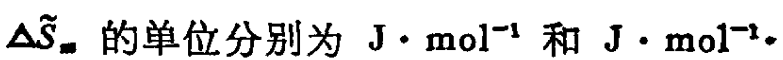
$\mathrm{K}^{-1}$. 式(2)可用来估算金属的熔化热 $\tilde{L}_{m}$ 和. 熔化熵 $\Delta \tilde{S}_{m}$.

用式 (2) 来估算的 $\tilde{L}_{m}$ 值与实验值基本 上是一致的. 除几种两性金属如 $\mathrm{Ge} 、 \mathrm{Sb} 、 \mathrm{Sn}$ 、 $\mathrm{Bi}$ 等的计算偏差较大外, 其余的计算值均接 近于实验数据. 对于全部 64 种金属,计算偏 差在 \pm 2.0 以内的有 53 个, 占全部金属的 $80 \%$ 以上, 由此说明式 (2) 的准确性是较高 的.

\section{梅 平 甘光奉}

(江汉石油学院应化系, 湖北沙市)

雷秀斌

(制州师范专科学校化学系, 湖北)

温元凯

(中国科学技术大学应用化学系,合肥)

\section{水稻原生质体 DAPI-DNA 的观察研究}

，DNA 专一荧光染料 DAPI (4'，6-diamidino-2-phenylindole) 据报道除借助复杂的 TAN 和 NS 缓冲液外就难于进入高等植物 原生质体而限制了其应用. 本文报道我们通 过加人适量 $\mathrm{Ca}^{2+}$ 将 DAPI 渗透到水稻花粉 愈伤组织原生质体中的结果。这一方法为高 等植物原生质体的遗传操作提供了快速简便 的检测技术。
用含 4\% 纤维索酶 (Onozuka R-10)、 $1.5 \%$ 果胶酶 $(\mathrm{Y}-23)$ 和 $0.85 \mathrm{~mol} / \mathrm{l}$ 甘露 醇、 $1 \mathrm{mmol} / 1 \mathrm{CaCl}_{2}$ 的 $\mathrm{pH} 5.4$ 混合酶液在 $34^{\circ} \mathrm{C}$ 恒温水浴中处理由花药离体培养所产 生的花粉愈伤组织 $10 \mathrm{~h}$, 按常规方法离心、洗 涤和提纯原生质体. 将一部分原生质体悬浮 在 $10 \mathrm{mmol} / 1 \mathrm{CaCl}_{2}$ 和 $0.75 \mathrm{~mol} / 1$ 甘露醇的 保存液中, 光镜相差观察时, 原生质体呈圆球 